foregoing, has written that "I find that the equation $\Delta S=R \ln V^{g} / V_{f}$ does define a volume $V_{f}$ that has a real significance independently of any model. The others depend on a model but not this one." My purpose in writing this letter has been to stir up discussion, not to dogmatize, therefore I hope that he will publish the analysis he gave in his letter to me.

The work on which this communication is based was supported by the U. S. Atomic Energy Commission.

${ }^{1}$ A. Bondi, J. Phys. Chem. 58, 929 (1954).

${ }^{2}$ J. G. Kirkwood, J. Chem. Phys. 18, 380 (1950).

3 E. Brian Smith and J. H. Hildebrand, J. Chem. Phys. 31, 145 (1959).

${ }^{4}$ Hirschfelder, Curtiss, and Bird, Molecular Theory of Gases and Liquids (John Wiley \& Sons, Inc., New York, 1954), p. 280.

${ }^{5} \mathrm{~J}$. H. Hildebrand, in Growth and Perfection of Crystals (John Wiley \& Sons, Inc., New York, 1958), p. 310.

${ }^{6} \mathrm{~J}$. H. Hildebrand and R. L. Scott, Solubility of Nonelectrolytes (Reinhold Publishing Corporation, New York, 1950), p. 99.

\section{NMR Spectra of Normal and Deuterated Methylacetylenes}

Wyman R. Vaughan and Robert C. Taylor

Department of Chemistry, University of Michigan, Ann Arbor, Michigan

(Received July 6, 1959)

$\mathbf{I}^{\mathrm{N}}$ $\mathrm{N}$ connection with physical studies on certain acetylenes we have had occasion to examine the NMR spectrum ${ }^{1}$ of methylacetylene (I) which surprisingly shows but one strong central line with a few weak satellites. It was suggested that failure to show the expected two distinct multiplets, a doublet from $\mathrm{CH}_{3}$ and a quadruplet from $\mathrm{C}-\mathrm{H}$, might be due either to fairly rapid proton exchange, contrary to chemical and spectroscopic evidence, or to nearly perfect accidental degeneracy in the resonance positions. ${ }^{2}$ If the protons are able to exchange rapidly, the separate and distinct existence of $\mathrm{CH}_{3} \mathrm{CCD}$ (II) and $\mathrm{CD}_{3} \mathrm{CCH}$ (III) should be unlikely.
To clarify this point, NMR spectra have been obtained from the compounds II and III. Compound II was prepared by repeated exchange of Matheson methylacetylene with $\mathrm{D}_{2} \mathrm{O}$ containing a trace of $\mathrm{NaOD}$. Treatment was continued until the infrared spectrum of the gas showed no acetylenic hydrogen absorption. Compound III was prepared by reacting $\mathrm{CD}_{3} \mathrm{CCD}$, generated from the action of $\mathrm{D}_{2} \mathrm{O}$ on magnesium carbide, ${ }^{3}$ with a solution of sodium in liquid ammonia to give the sodium salt. After removal of the ammonia, the salt was decomposed with $\mathrm{H}_{2} \mathrm{O}$ to give III. All operations were carried out in a closed system. The spectra were obtained from liquid samples containing a trace of tetramethylsilane and sealed under pressure in standard 5-mm o. d. Pyrex tubing. The instrument used was a Varian V-4300C High Resolution NMR Spectrometer operating at $60 \mathrm{Mc}$. Measurements were made at $24^{\circ} .{ }^{1}$ For each substance as well as for $I$, the central line falls at $106 \mathrm{cps}$ on the low field side of the reference.

In contrast to the spectrum of I, that of II (Fig. 1) nicely illustrates the triplet arising from splitting of the methyl resonance line by spin-coupling to the deuteron $($ spin $=1)$. The triplet, measured by the "wiggle beat" method, is spaced 0.52 cps.

Similarly, III gives a multiplet pattern appearing to conform to the 10 line pattern expected from spincoupling of the proton to three equivalent deuterons (total spin =3). The spacing of this multiplet is 0.48 cps, also measured by the "wiggle beat" method. Since the measurements are probably good to $\pm 0.01 \mathrm{cps}$, the difference in spacing of the multiplets from II and III may be attributable to an isotope effect. ${ }^{2}$

Since the central lines of the spectral patterns for I, II, and III all fall at nearly the same position, it is clear that the unusual spectrum of $I$ is due to other causes than exchange phenomena and resembles an accidental degeneracy in which lines arising from the two types of protons happen to fall at precisely the same position.

We wish to acknowledge the assistance of Professor Richard B. Bernstein of this department, who furnished

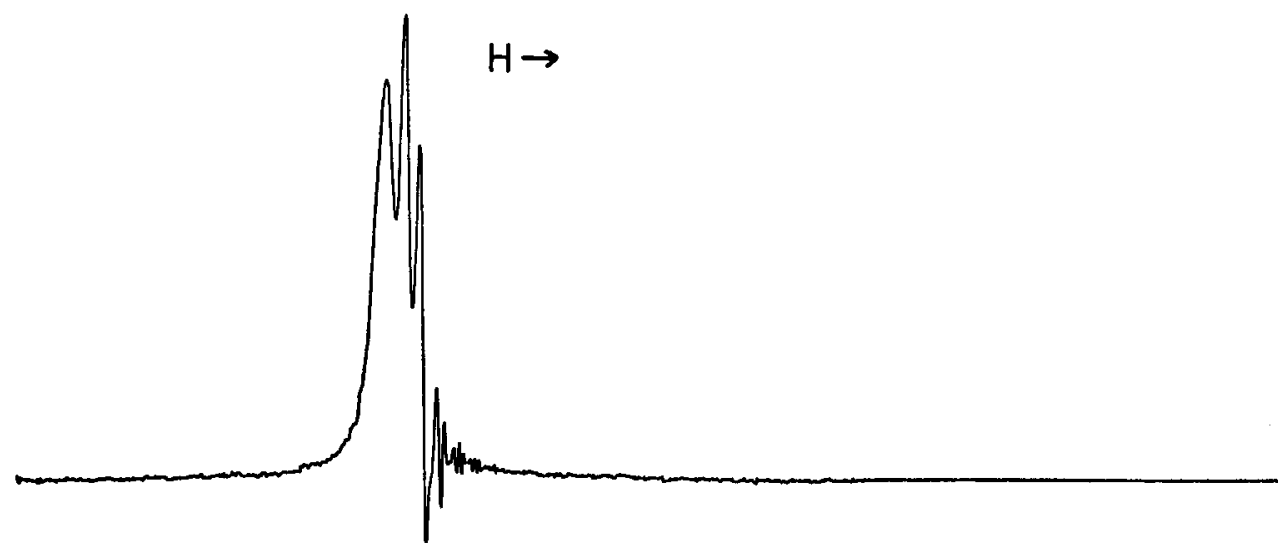

FIG. 1. Proton nuclear magnetic resonance spectrum of $\mathrm{CH}_{3} \mathrm{CCD}$ at $60 \mathrm{Mc}$ (Triplet spacing $0.52 \mathrm{cps}$.) 
the sample of II; of Mr. Robert L. Amster, who prepared exceedingly pure samples of $\mathrm{III}$; and of $\mathrm{Mr}$. Ronald Dehl, who obtained preliminary NMR spectra of all three compounds at $40 \mathrm{Mc}$. We also wish to acknowledge the cooperation and assistance of Dr. James N. Schoolery of Varian Associates in obtaining the final high-resolution spectra.

${ }^{1}$ Kindly provided by Dr. James N. Schoolery, Varian Associates, Palo Alto, California.

${ }^{2} \mathrm{~J}$. N. Schoolery (private communication). The detailed analysis of the methylacetylene spectrum will be discussed by him in a forthcoming publication.

${ }^{3}$ L. C. Leitch and R. Renaud, Can. J. Chem. 30, 79 (1952).

\section{Negative Ion-Molecule Reactions*}

\author{
A. Henglein and G. A. Muccini \\ Radiation Research Laboratories, Mellon Institute, \\ Pittsburgh, Pennsylvania
}

(Received July 27, 1959)

$\mathrm{I}^{\mathrm{I}}$ $\mathrm{N}$ recent years numerous reactions between positive ions and neutral molecules have been observed in mass spectrometers ${ }^{1-3}$ and these reactions have been satisfactorily explained by theory. ${ }^{2,4,5}$ The $\mathrm{I}_{3}^{-}$ion, which has been observed to be formed by a secondary process following electron capture by iodine, ${ }^{6}$ seems to be the only analogous reaction reported to date between negative ions and molecules. We have investigated a number of systems in which such processes might be expected. The reactions observed to date, which include several electron transfer processes, are compiled in Table I. A Consolidated Electrodynamics
Corporation Model 21-103C mass spectrometer was used in these experiments after appropriate changes had been made for the measurement of appearance potentials of negative ions. In most of the work sulfur dioxide ${ }^{7}$ was used as an intense source of the primary ions $\mathrm{SO}^{-}$ and $\mathrm{O}^{-}$. The appearance potentials and the form of the ionization efficiency curves for the secondary ions given in the table agree with those of the primary ions required for the reaction. Furthermore, the ratio $i_{s} / i_{p}$ of the primary to secondary ion current was always found to increase linearly with increasing gas pressure in the ionization chamber. This current ratio was measured at identical conditions of operation, i.e., at constant pressure and repeller field strength. Since $i_{s} / i_{p}$ is proportional to the product of the cross section and the length of the path of the primary ions in the ionization chamber, relative cross sections can be calculated from the measured current ratios. The well-known positive ion-molecule reaction of water ${ }^{8}$ was taken as standard. However, it seems doubtful that the length of the path of the ions in the chamber has the same value for positive and negative ions since the latter have to be produced at very low electron energies at which the field due to space charge may influence the repeller field in an unpredictable manner. The relative cross sections given in the table should therefore be only regarded as approximate.

The reactions of the $\mathrm{O}^{-}$ion include iodine abstraction to form $\mathrm{OI}^{-}$, proton transfer to give $\mathrm{OH}$ and the simultaneous transfer of a proton and a hydrogen atom to form $\mathrm{H}_{2} \mathrm{O}$. The latter process must be postulated for the observed reaction with nitromethane which otherwise would be endothermic. The cross section for iodine abstraction decreases with increasing electron affinity

TABLE I. Negative ion-molecule reactions.

\begin{tabular}{|c|c|c|c|c|}
\hline \multicolumn{5}{|c|}{ (Repeller field: $4 \mathrm{ev} / \mathrm{cm}$. Total gas pressure in the reservoir: $500 \mu$ ) } \\
\hline Gas $^{a}$ & $\begin{array}{l}\text { Appearance potentials of the primary and } \\
\text { secondary ions in volts }\end{array}$ & Reaction & $i_{s} / i_{p} \times 10^{3}$ & $\begin{array}{l}\text { Relative cross } \\
\text { section }^{b}\end{array}$ \\
\hline $\mathrm{SO}_{2}-\mathrm{CH}_{3} \mathrm{I}$ & 3.5 and 5.9 & $\mathrm{O}^{-}+\mathrm{CH}_{3} \mathrm{I} \rightarrow \mathrm{OI}^{-}+\mathrm{CH}_{3}$ & 4.0 & 1.3 \\
\hline $\mathrm{SO}_{2}-\mathrm{I}_{2}$ & 3.5 and 5.9 & $\mathrm{O}^{-}+\mathrm{I}_{2} \rightarrow \mathrm{OI}^{-}+\mathrm{I}$ & 2.0 & 0.64 \\
\hline $\mathrm{SO}_{2}^{-} \mathrm{IBr}$ & 3.5 and 5.9 & $\mathrm{O}^{-}+\mathrm{IBr} \rightarrow \mathrm{OI}^{--}+\mathrm{Br}$ & 0.12 & 0.04 \\
\hline $\mathrm{SO}_{2}-\mathrm{CH}_{3} \mathrm{NO}_{2}$ & 3.5 and 5.9 & $\begin{aligned} \mathrm{O}^{-}+\mathrm{CH}_{3} \mathrm{NO}_{2} & \rightarrow \mathrm{CH}_{2} \mathrm{NO}_{2}^{-}+\mathrm{OH}^{-} \\
& \rightarrow \mathrm{CHNO}_{2}^{-}+\mathrm{H}_{2} \mathrm{O}\end{aligned}$ & $\begin{array}{l}8.0 \\
4.4\end{array}$ & $\begin{array}{l}2.6 \\
1.4\end{array}$ \\
\hline $\mathrm{CH}_{3} \mathrm{NO}_{2}$ & Nearly zero, 3.2 and 7.0 & $\mathrm{O}^{-}+\mathrm{CH}_{3} \mathrm{NO}_{2} \rightarrow \mathrm{CH}_{2} \mathrm{NO}_{2}^{-}+\mathrm{OH}$ & 20 & 3.2 \\
\hline $\mathrm{SO}_{2}$ & 3.9 and 5.8 & $\mathrm{SO}^{-}+\mathrm{SO}_{2} \rightarrow \mathrm{SO}_{2}^{--}+\mathrm{SO}$ & 15 & 2.4 \\
\hline $\mathrm{SO}_{2}-\mathrm{C}_{6} \mathrm{H}_{5} \mathrm{NO}_{2}$ & Nearly zero & $\mathrm{C}_{6} \mathrm{H}_{5} \mathrm{NO}_{2}{ }^{-}+\mathrm{SO}_{2} \rightarrow \mathrm{SO}_{2}{ }^{-}+\mathrm{C}_{6} \mathrm{H}_{5} \mathrm{NO}_{2}$ & 47 & 15 \\
\hline $\mathrm{NO}_{2}$ & 2.1 and 3.4 and 6.5 & $\mathrm{O}^{-}+\mathrm{NO}_{2} \rightarrow \mathrm{NO}_{2}^{-}+\mathrm{O}$ & 18 & 2.9 \\
\hline $\mathrm{H}_{2} \mathrm{O}$ & & $\mathrm{H}_{2} \mathrm{O}^{+}+\mathrm{H}_{2} \mathrm{O} \rightarrow \mathrm{H}_{3} \mathrm{O}^{+}+\mathrm{OH}$ & 6.2 & $1^{c}$ \\
\hline
\end{tabular}

a In the gas mixtures $\mathrm{SO}_{2}$ is present at a mole fraction of 0.5 .

$\left.\mathrm{b}\left(i_{8} / i_{p}\right) /{ }^{i} \mathrm{H}_{3} \mathrm{O}^{+} /{ }^{i} \mathrm{H}_{2} \mathrm{O}^{+}\right)$for single components and $\left(2 i_{s} / i_{p}\right) /\left({ }^{i} \mathrm{H}_{3} \mathrm{O}^{+} /{ }^{i} \mathrm{H}_{2} \mathrm{O}^{+}\right)$for two components in the gas.

c The absolute cross section is about $130 \mathrm{~A}^{2}$ at a repeller field of $4 \mathrm{ev} / \mathrm{cm}$ (calculated from reference 8 ). 